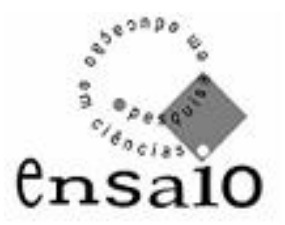

Vol. 10 no. 1 jun. 2008

\title{
Levantamento das principais dificuldades dos estudantes utilizando dados de processos seletivos
}

\author{
Survey of major problems of students using data of selection procedure \\ José Guilherme Moreira ${ }^{1}$ \\ Valmária Gomes Filgueira ${ }^{2}$
}

\section{Resumo}

Através de dados de processos seletivos, propomos uma forma de análise para levantar as principais dificuldades dos estudantes de Ensino Médio com conteúdos de física ministrados nesse nível de ensino. Nessa análise, utilizamos os dados dos questionários socioeconômicos dos candidatos aos vestibulares da UFMG e os resultados de algumas questões de física desses vestibulares. Assim foi possível correlacionar a atratividade das alternativas com dados socioeconômicos - tipo de escola freqüentado na maior parte do ensino médio e grau de escolaridade dos pais. Notamos que as dificuldades dos estudantes diferem de acordo com o grupo socioeconômico ao qual pertencem e, com esse dado, tentamos entender como evolui a compreensão dos estudantes sobre o tópico abordado nessas questões.

Palavras Chaves: ensino de física; processos seletivos, fatores socioeconômicos.

\begin{abstract}
Using data of selective processes, we propose a way to verify the main difficulties of the high school students with physics contents learning in this degree. In this analysis, we used data of the socioeconomic questionnaires that the candidates of the selective process of UFMG filled in and the results of some physics questions of this process. Thus it is possible to relate the attractiveness of the alternative with the socioeconomic data - kind of school they have been to for most time of their high school and their parents schooling. We noted that the difficulties of the students were different to each socioeconomic group and, with this result, we try to understand how the comprehension of the students about the topics concerned in these questions evolves.
\end{abstract}

Keywords: physics teaching, selective process, socioeconomic factors.

\footnotetext{
${ }^{1}$ Departamento de Física - ICEx - UFMG (jmoreira@fisica.ufmg.br)

${ }^{2}$ Departamento de Física - ICEx - UFMG (valmaria@fisica.ufmg.br)
} 


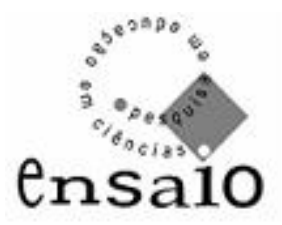

\section{Introdução}

Vol. 10 no. 1 jun. 2008

Nos últimos 10 anos, os processos seletivos (vestibulares) para os cursos de graduação da Universidade Federal de Minas Gerais (UFMG) contam com grande número de candidatos - mais de 60 mil por ano - que preenche um amplo espectro socioeconômico. Na $1^{\mathrm{a}}$ etapa desse processo, todos os candidatos, independente da opção de curso, têm que realizar provas fechadas das oito disciplinas tradicionais, incluindo uma prova de Física. Essa prova, conforme descrito no Manual do Candidato para o Vestibular 2006,

“... tem por objetivo avaliar o candidato quanto ao conhecimento e à compreensão de conceitos fundamentais da Física e à aplicação desses conceitos na interpretação de fenômenos naturais, de fatos da vida cotidiana, de experimentos simples e de aplicações tecnológicas. Nessa etapa, a ênfase é mais conceitual e qualitativa e menos matemática e quantitativa." [UFMG, 2005].

Assim, as questões dessas provas são simples, procuram abordar situações do cotidiano e esperava-se que não apresentassem dificuldades para a maioria dos estudantes que concluíram o Ensino Médio.

A motivação para o nosso trabalho vem dos baixos índices de acerto para algumas questões dessa prova. Usando a atratividade das alternativas dessas questões e os dados socioeconômicos dos candidatos, procuramos detectar as dificuldades dos estudantes com o conteúdo de física envolvido. Para isso, separamos os candidatos em grupos através de dois fatores socioeconômicos - tipo de escola na qual cursou o Ensino Médio e escolaridade dos pais - e levantamos o desempenho de cada grupo nas questões selecionadas. Através da análise dos desempenhos dos vários grupos, procuramos detalhar os níveis de dificuldade dos estudantes no tópico abordado.

Trabalhar com dados de uma prova de múltipla escolha de um vestibular pode levantar uma série de questionamentos:

- por se tratar de um teste fechado, os candidatos são induzidos a marcar uma das alternativas e o tipo de raciocínio que o candidato desenvolveu não se encontra explícito; 


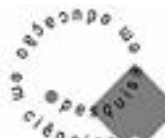 \\ ensalo}

Vol. 10 no. 1 jun. 2008

- a tensão dos candidatos na hora da prova pode influenciar seu desempenho e, provavelmente, alguns candidatos escolheram aleatoriamente a resposta à questão;

- a prova foi elaborada com o intuito de selecionar candidatos e não com o objetivo de avaliá-los ou detectar dificuldades de aprendizagem;

- muitos candidatos fizeram um cursinho pré-vestibular, sendo treinados para fazer uma prova de múltipla escolha, de forma que podem ter acertado a questão sem possuir o conhecimento real do conteúdo.

Além disso, vamos utilizar os dados estatísticos diretos, o que remete à teoria clássica dos testes. Não serão utilizadas teorias mais elaboradas, como a teoria de resposta ao item, que poderiam atenuar alguns dos fatores relatados acima.

Apesar desses questionamentos, existem alguns fatores que justificam a utilização desses dados:

- o fato de trabalharmos com um grande número de candidatos permite detectarmos as dificuldades dos estudantes em determinado tópico;

- os candidatos têm um perfil socioeconômico bastante diversificado, assim não nos restringimos a avaliar somente uma classe ou grupo social.

Na seção a seguir, detalhamos a metodologia que iremos empregar e, depois, apresentamos uma breve utilização dessa metodologia em quatro questões - uma de força e movimento, uma de transformações termodinâmicas, outra de eletrização junto com ação-reação e, por fim, em uma questão de circuitos elétricos. Na última seção, apresentamos as primeiras conclusões que essa breve utilização proporcionou e descrevemos rapidamente as perspectivas geradas por este trabalho.

\section{Metodologia}

A COPEVE/UFMG - Comissão Permanente do Vestibular da UFMG - possui arquivos, desde o vestibular de 1995, com todas as informações dos candidatos inscritos a seus processos seletivos - desde dados pessoais até cada alternativa sinalizada nas questões das provas de múltipla escolha, passando pelas respostas ao questionário socioeconômico. O vestibular da UFMG é constituído de duas etapas: na $1^{\text {a }}$, os candidatos 


\section{8 \\ ensalo}

Vol. 10 no. 1 jun. 2008

realizam 8 provas fechadas - Biologia, Física, Geografia, História, Língua Estrangeira (Espanhol, Francês ou Inglês), Matemática, Português e Química - e, na $2^{\mathrm{a}}$ etapa, provas abertas de disciplinas afins da opção de curso. As provas de $1^{\mathrm{a}}$ etapa, a partir de 1998 , passaram a ter 15 questões com 4 alternativas. É feita uma única prova que contém 4 versões (cadernos) semelhantes, diferindo somente na ordem das suas alternativas. Para a realização deste trabalho, a COPEVE nos repassou arquivos com todos esses dados, com exceção dos que permitem a identificação dos candidatos.

Com esses arquivos, conseguimos levantar informações sobre as questões de múltipla escolha, correlacionando-as com fatores socioeconômicos dos candidatos. Uma das informações mais importantes para o desenvolvimento deste trabalho é a atratividade de cada alternativa da questão, isto é, o percentual de candidatos dentro de um certo grupo socioeconômico, que optaram por uma determinada alternativa. Para levantar a atratividade de cada alternativa consideramos a resposta em todos os cadernos, que eram apresentadas em ordens diferentes. Com isso, a preferência por uma determinada letra, que pode desvirtuar a análise estatística, pode ser considerada desprezível.

Os grupos socioeconômicos que vamos trabalhar neste artigo são:

- o tipo de escola freqüentada pelo candidato no Ensino Médio - pública municipal/estadual ou particular ou pública federal;

- a escolaridade dos pais - Fundamental (nenhum dos pais tem o Ensino Médio completo), Médio (pelo menos um deles completou o Ensino Médio ou tem o superior incompleto), Superior 1 (apenas um dos pais tem o Ensino Superior completo) e Superior 2 (ambos têm nível superior).

Esses grupos são definidos através das respostas que os candidatos fornecem na inscrição a duas questões presentes em um questionário socioeconômico (UFMG, 2005), apresentadas nos Quadros 1 e 2. 


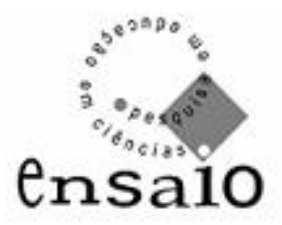

Vol. 10 no. 1 jun. 2008

Quadro 1: Pergunta referente ao tipo de escola freqüentada pelo candidato no Ensino Médio.

\begin{tabular}{|l|l|}
$\begin{array}{l}\text { Em que tipo de escola você cursou, integralmente, ou em sua maior parte, o Ensino } \\
\text { Médio? }\end{array}$ \\
\hline Em escola pública federal & Em escola pública municipal \\
\hline Em escola pública estadual & Em escola particular \\
\hline
\end{tabular}

Quadro 2: Pergunta referente à escolaridade do pai. Os candidatos respondem a uma outra questão igual a essa com relação à escolaridade da mãe.

\begin{tabular}{|l|l|}
\hline Qual o nível de escolaridade de seu pai? \\
\hline Nenhum & Ensino Médio incompleto \\
\hline Ens. Fundamental incompleto até a $4^{\mathrm{a}}$ série & Ensino Médio completo \\
\hline Ens. Fundamental incompleto após a $4^{\mathrm{a}}$ série & Ensino Superior incompleto \\
\hline Ensino Fundamental completo & Ensino Superior completo \\
\hline
\end{tabular}

Nos gráficos 1 e 2 podemos verificar o perfil dos candidatos inscritos ao processo seletivo da UFMG. Ao longo dos anos esse perfil sofre poucas alterações, por isso representamos somente os dados referentes ao vestibular de 2005. Uma tabela com dados referentes aos outros anos encontra-se no apêndice deste artigo.

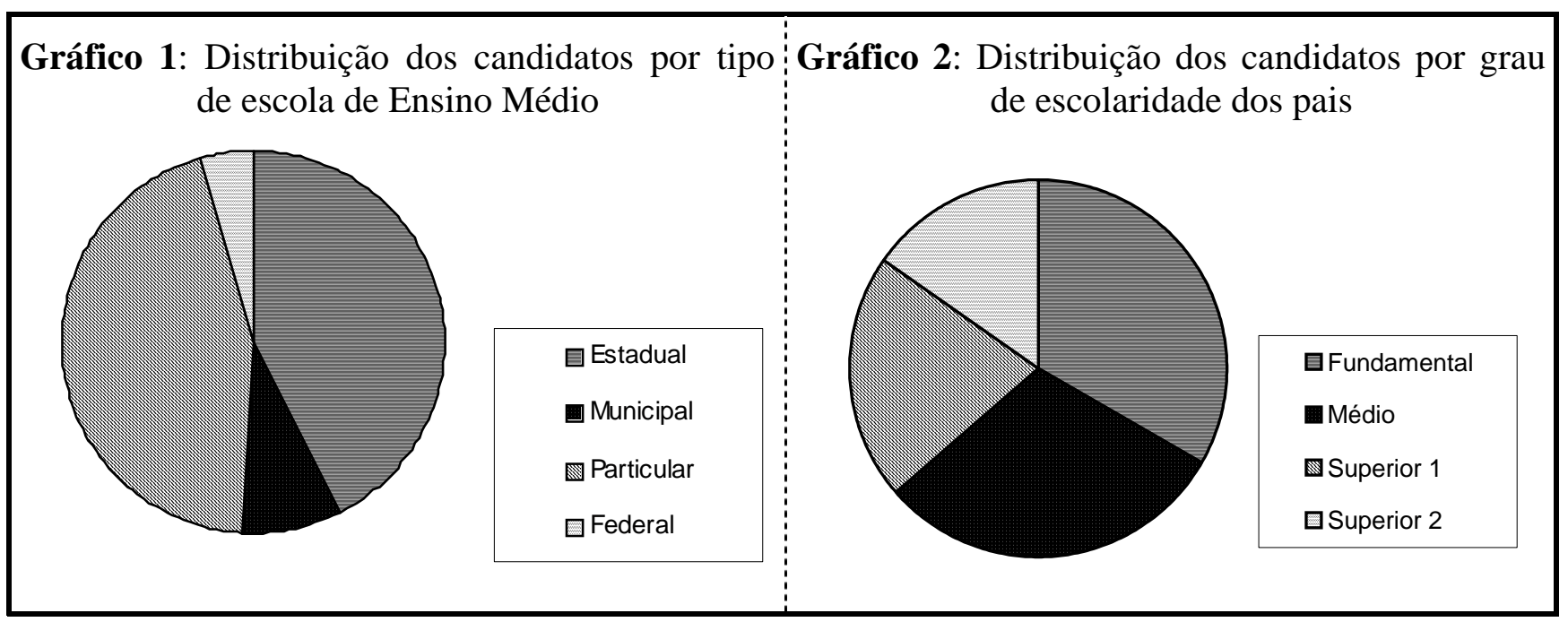




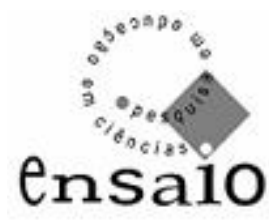

Vol. 10 no. 1 jun. 2008

O gráfico 3 apresenta a nota média dos candidatos no total da $1^{\text {a }}$ etapa (primeira barra) e na prova de Física (segunda barra), no geral e para cada grupo socioeconômico.

Gráfico 3: Nota média dos candidatos, no geral e por grupos socioeconômicos.

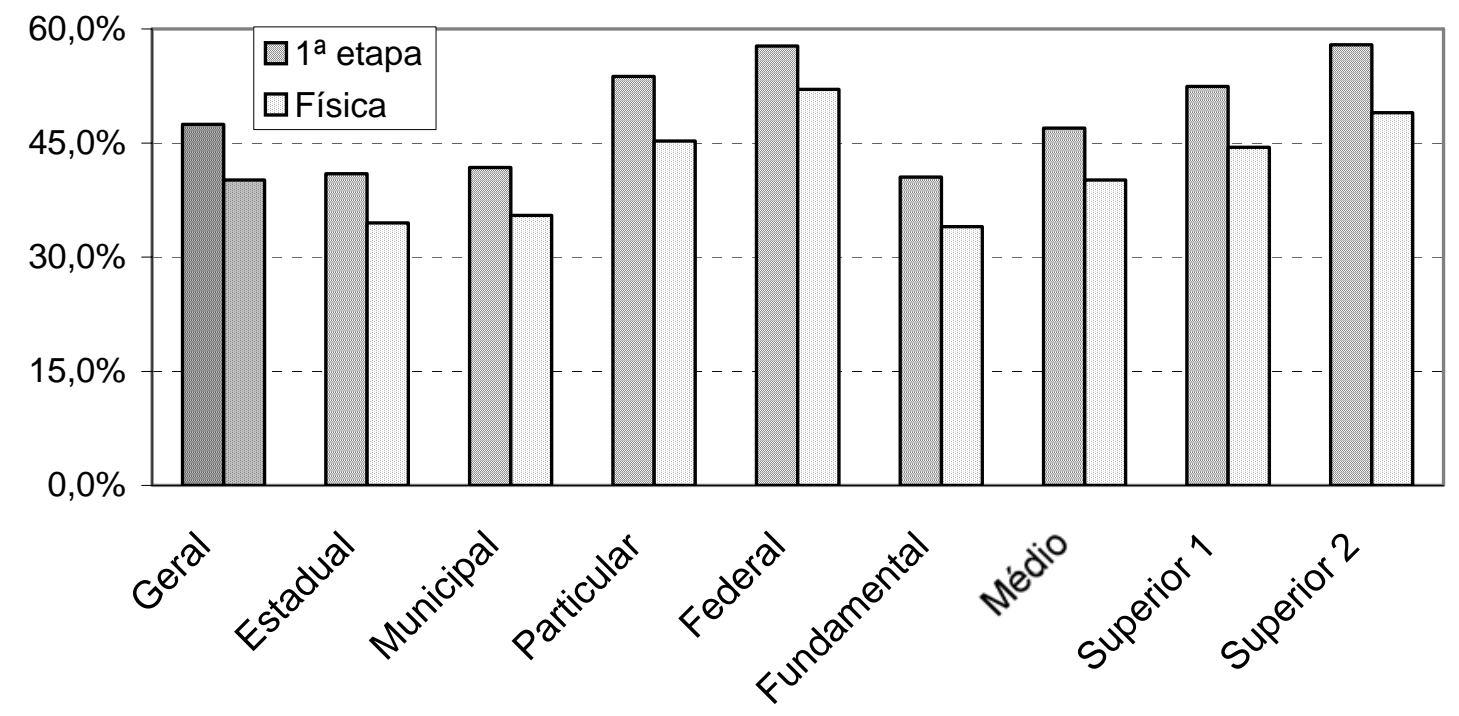

Percebemos que tanto os candidatos oriundos de escola pública quanto aqueles que têm pais com baixa escolaridade apresentam desempenho mais baixo que os outros. Percebemos, também, que os alunos das escolas federais apresentaram um desempenho semelhante ao das particulares, mas na prova de física, destacaram-se mais que estes. Atribuímos esse resultado ao fato de a maioria dos candidatos das escolas federais ter realizado curso técnico na área de ciências exatas.

O desempenho dos grupos socioeconômicos menos privilegiados estar abaixo da média não é nenhuma surpresa, mas não é esse o dado que será objeto de análise deste trabalho. Nossa análise será focada na atratividade das alternativas erradas e como essa atratividade muda com o grupo socioeconômico. Com essas informações, achamos que é possível detectar dificuldades que os candidatos apresentam ou deficiências que tiveram em sua formação. 


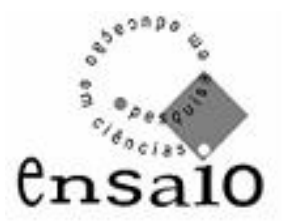

Vol. 10 no. 1 jun. 2008

Para exemplificar essa metodologia, selecionamos quatro questões com diferentes tópicos de Física - força e movimento; transformações termodinâmicas e conservação da energia; eletrização junto com ação-reação; e circuitos elétricos. Tentamos escolher questões que apresentam conteúdos que consideramos relevantes e que exigem análise por parte dos candidatos. Excluímos aquelas que são resolvidas por aplicação direta de fórmulas e que não exigem raciocínio físico. Além disso, selecionamos questões que tiveram um bom índice de discriminação - índice que avalia quanto a questão contribuiu para diferenciar os candidatos, de acordo com o desempenho de cada um no resultado geral. Esse índice é um número no intervalo $[-1,1]$ e, para questões de múltipla escolha, com um público tão heterogêneo como o da $1^{\mathrm{a}}$ etapa do vestibular da UFMG, um valor superior a 0,3 indica que a questão apresentou boa discriminação e acima de 0,5, excelente.

\section{Aplicações da Metodologia}

Agora, com o intuito de exemplificar a metodologia proposta, apresentaremos quatro questões abordando diferentes temas em física e faremos uma breve análise dos conceitos envolvidos nas mesmas. Abaixo de cada questão apresentaremos uma tabela que indica a atratividade de cada alternativa entre os grupos socioeconômicos avaliados.

Começaremos nossa análise pela questão 02 da prova de 2001 (Quadro 3) na qual pede-se para indicar a alternativa que melhor representa as forças que atuam em uma bola em determinado ponto de sua trajetória [ALVES et al., 2001]. 


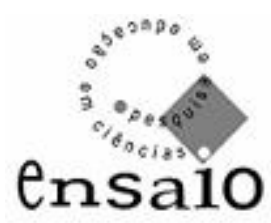

Vol. 10 no. 1 jun. 2008

Quadro 3 - Questão 02 do vestibular de 2001 que teve índice de discriminação de 0,50.

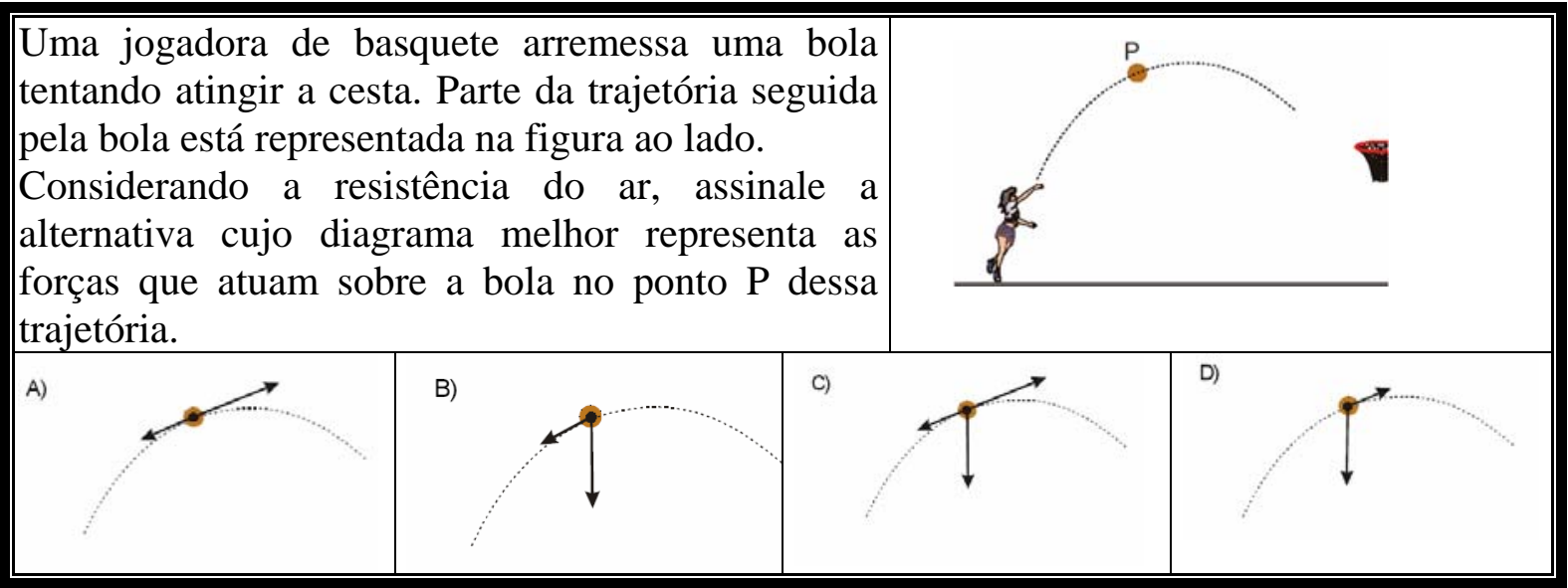

Tabela 1: Atratividade das alternativas da questão 02/2001, de acordo com os grupos socioeconômicos. Nesta tabela e nas seguintes, a linha da alternativa correta está hachurada e a alternativa com maior atratividade em cada grupo está em negrito e sublinhada.

\begin{tabular}{|c|c|c|c|c|c|c|c|c|}
\hline \multirow{2}{*}{\multicolumn{2}{|c|}{ Geral }} & \multicolumn{3}{|c|}{ Escolas } & \multicolumn{4}{|c|}{ Escolaridade dos Pais } \\
\hline & & Pública & Particular & Federal & Fundamental & Médio & Superior 1 & Superior 2 \\
\hline A & $5.1 \%$ & $8.6 \%$ & $3.0 \%$ & $2.4 \%$ & $9.6 \%$ & $4.9 \%$ & $3.0 \%$ & $1.9 \%$ \\
\hline $\mathrm{B}$ & $20.8 \%$ & $14.8 \%$ & $25.9 \%$ & $28.0 \%$ & $14.7 \%$ & $18.4 \%$ & $24.6 \%$ & $32.6 \%$ \\
\hline $\mathrm{C}$ & $44.4 \%$ & $39.1 \%$ & 47.4\% & $\underline{51.0 \%}$ & $39.3 \%$ & $\underline{46.1 \%}$ & $\underline{47.8 \%}$ & $\underline{45.8 \%}$ \\
\hline $\mathrm{D}$ & $29.9 \%$ & $37.5 \%$ & $23.7 \%$ & $18.5 \%$ & $36.3 \%$ & $30.7 \%$ & $24.5 \%$ & $19.7 \%$ \\
\hline
\end{tabular}

Ao observar a tabela 1, reparamos que, independente do grupo socioeconômico, a alternativa mais marcada (a $\mathbf{C}$ ) é aquela que, além das forças que realmente atuam no corpo - peso e atrito -, há uma força cujo sentido é o mesmo do movimento. Podemos perceber que, no geral, aproximadamente 79\% dos candidatos acreditam na existência dessa força aristotélica ${ }^{3}$ porque sinalizaram as alternativas A, C ou D. Esta é uma idéia

\footnotetext{
${ }^{3}$ Segundo as concepções de Aristóteles, só existe movimento se houver uma força na mesma direção desse movimento. Neste trabalho, vamos chamar de força aristotélica à força que tem essa mesma concepção.
} 


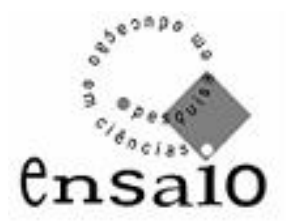

Vol. 10 no. 1 jun. 2008

bastante comum entre estudantes do ensino médio e está relacionada com concepções espontâneas (VIENNOT, 1979; ZYLBERSZTAJN, 1983; PACCA, 1984; VILLANI et al., 1985; HESTENES et al., 1992; PEDUZZI et al., 1992; KALMAN et al., 2004), ou seja, raciocínios intuitivos sobre um determinado fenômeno envolvendo conceitos préconcebidos, às vezes, de forma errônea. Um trabalho mais detalhado sobre esse conceito em questões do Vestibular da UFMG foi desenvolvido por Souza e Moreira (2004).

É interessante notar que tanto a alternativa correta (a B) quanto a alternativa que somente acrescenta essa força aristotélica (a $\mathbf{C}$ ) apresentam índices de atratividade que aumentam com a escolaridade dos pais e mudam com o tipo de escola - sendo menor nas escolas públicas e maior nas escolas particulares e federais. A alternativa $\mathbf{A}$ tem uma atratividade abaixo de 10\%, chegando a ser desprezível (abaixo de 4\%) para os grupos socioeconômicos mais favorecidos. No entanto, a alternativa D, embora esteja com atratividade pouco abaixo de $20 \%$ para esses grupos, chega acima de 0,35 nos grupos menos favorecidos, semelhante à atratividade da alternativa C. Como já sinalizado por Souza e Moreira (2004), esse resultado parece indicar que os candidatos que marcaram essa alternativa apresentam maior dificuldade daqueles que marcaram a $\mathbf{C}$, pois não conseguiram ler e interpretar a questão corretamente já que ignoraram um dado explícito na questão que é a resistência do ar.

A segunda questão que iremos analisar é do ano de 2004 (Quadro 4) e aborda transformações gasosas e a $1^{\text {a }}$ lei da termodinâmica. Nessa questão, um gás dentro de um cilindro com um êmbolo móvel é aquecido e os candidatos deveriam identificar o que acontece com a pressão no recipiente e com a energia interna do gás e o calor a ele fornecido [ALVES et al., 2004]. 


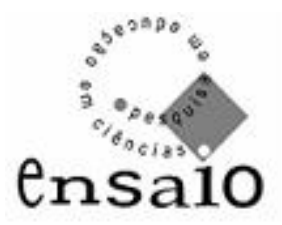

Vol. 10 no. 1 jun. 2008

Quadro 4 - Questão 06 do vestibular de 2004 que teve índice de discriminação de 0,53.

Um cilindro é fechado por um êmbolo que pode se mover livremente. Um gás, contido nesse cilindro, está sendo aquecido, como representado na figura.

Com base nessas informações, é CORRETO afirmar que, nesse processo

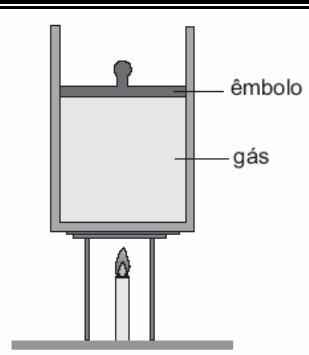

A) a pressão do gás aumenta e o aumento da sua energia interna é menor que o calor fornecido.

B) a pressão do gás permanece constante e o aumento da sua energia interna é igual ao calor fornecido.

C) a pressão do gás aumenta e o aumento da sua energia interna é igual ao calor fornecido.

D) a pressão do gás permanece constante e o aumento da sua energia interna é menor que o calor fornecido.

Analisando a tabela 2, podemos notar um resultado curioso: a alternativa $\mathbf{C}$ foi a mais marcada por quase todos os grupos, embora essa seja a opção em que as duas afirmativas - o que acontece com a pressão no recipiente e a comparação do calor fornecido com a variação da energia interna do gás - não estão corretas. Este fato nos indica que os estudantes apresentam dificuldades tanto na análise de transformações gasosas, quanto no uso da $1^{\mathrm{a}}$ lei da termodinâmica.

Tabela 2: Atratividade das alternativas da questão 06/2004, de acordo com o grupo socioeconômico.

\begin{tabular}{|l|c|c|c|c|c|c|c|c||}
\hline \multirow{2}{*}{ Geral } & \multicolumn{3}{|c|}{ Escolas } & \multicolumn{3}{c||}{ Escolaridade Pais } \\
\cline { 2 - 9 } & Pública & Particular & Federal & Fundamental & Médio & Superior 1 & Superior 2 \\
\hline A & $19.2 \%$ & $19.3 \%$ & $19.3 \%$ & $17.3 \%$ & $19.2 \%$ & $19.5 \%$ & $19.7 \%$ & $18.1 \%$ \\
\hline B & $20.0 \%$ & $19.9 \%$ & $20.0 \%$ & $21.0 \%$ & $20.4 \%$ & $19.6 \%$ & $20.2 \%$ & $19.9 \%$ \\
\hline C & $\mathbf{4 2 . 4 \%}$ & $\mathbf{4 7 . 9 \%}$ & $\mathbf{3 6 . 5 \%}$ & $\mathbf{3 5 . 4 \%}$ & $\underline{\mathbf{4 7 . 3} \%}$ & $\underline{\mathbf{4 4 . 1} \%}$ & $\mathbf{3 7 . 5 \%}$ & $30.8 \%$ \\
\hline D & $18.4 \%$ & $12.8 \%$ & $24.1 \%$ & $26.3 \%$ & $13.0 \%$ & $16.7 \%$ & $22.4 \%$ & $\underline{\mathbf{3 1 . 2} \%}$ \\
\hline
\end{tabular}




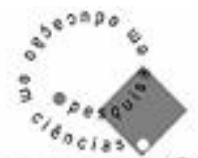 \\ ensa10}

Vol. 10 no. 1 jun. 2008

Somente $38.4 \%$ dos candidatos souberam identificar que a pressão no gás permanece constante (soma das atratividades das alternativas B e D) e $37.6 \%$ identificaram que o gás está realizando um trabalho, por isso o aumento da sua energia interna deve ser menor do que o calor fornecido a ele (soma de A e $\mathbf{C}$ ). Podemos destacar também que as alternativas A e B - nas quais só uma das afirmativas está correta tiveram atratividades da ordem de $20 \%$ para todos os grupos socioeconômicos. Isso parece significar que, quando se passa para grupos mais privilegiados, a atratividade da alternativa C, que tem as duas afirmativas erradas, decresce na mesma proporção que a atratividade da alternativa correta aumenta.

Nesta questão, como na anterior, o fator que mais influenciou no bom desempenho do candidato foi a escolaridade dos pais - o único grupo em que a alternativa correta teve a maior atratividade foi o Superior 2 .

Quadro 5 - Questão 12 do vestibular de 2003 que teve índice de discriminação de 0,49.

Aproximando-se um pente de um pedacinho de papel, observa-se que não há força entre eles. No entanto, ao se passar o pente no cabelo e, em seguida, aproxima-lo do pedacinho de papel, este será atraído pelo pente.

Sejam $F_{\text {pente }}$ e $F_{\text {papel }}$ os módulos das forças eletrostáticas que atuam, respectivamente, sobre o pente e sobre o papel.

Com base nessas informações, é CORRETO afirmar que

A) o pente está eletricamente carregado, o papel está eletricamente neutro e $F_{\text {pente }}=F_{\text {papel }}$.

B) o pente e o papel têm cargas de sinais opostos e $F_{\text {pente }}=F_{\text {papel }}$.

C) o pente e o papel têm cargas de sinais opostos e $F_{\text {pente }}>F_{\text {papel }}$.

D) o pente está eletricamente carregado, o papel está eletricamente neutro e $F_{\text {pente }}>F_{\text {papel. }}$

A próxima questão (Quadro 5) é do vestibular de 2003 e mistura dois tópicos: eletrização e a $3^{\mathrm{a}}$ Lei de Newton. Os candidatos tinham que conhecer os processos de eletrização por atrito e por indução e comparar as forças em um par ação-reação [ALVES et al., 2003]. 


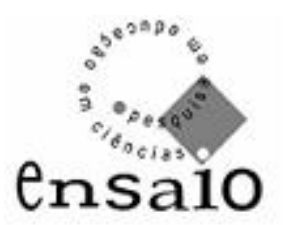

Vol. 10 no. 1 jun. 2008

Tabela 3: Atratividade das alternativas da questão 12/2003 de acordo com o grupo socioeconômico.

\begin{tabular}{|l|c|c|c|c|c|c|c|c||}
\hline \multirow{2}{*}{ Geral } & \multicolumn{3}{|c|}{ Escolas } & \multicolumn{4}{c||}{ Escolaridade Pais } \\
\cline { 2 - 9 } & Pública & Particular & Federal & Fundamental & Médio & Superior 1 & Superior 2 \\
\hline A & $27.0 \%$ & $20.0 \%$ & $34.7 \%$ & $\mathbf{4 0 . 4 \%}$ & $19.5 \%$ & $26.2 \%$ & $33.8 \%$ & $40.0 \%$ \\
\hline B & $9.6 \%$ & $10.3 \%$ & $8.5 \%$ & $10.0 \%$ & $10.9 \%$ & $9.3 \%$ & $8.7 \%$ & $7.9 \%$ \\
\hline C & $15.0 \%$ & $18.9 \%$ & $10.5 \%$ & $9.7 \%$ & $20.1 \%$ & $14.3 \%$ & $10.5 \%$ & $8.4 \%$ \\
\hline D & $\mathbf{4 8 . 4 \%}$ & $\mathbf{5 0 . 8 \%}$ & $\mathbf{4 6 . 4 \%}$ & $40.0 \%$ & $\underline{49.5 \%}$ & $\underline{\mathbf{5 0 . 2 \%}}$ & $\underline{\mathbf{4 6 . 9 \%}}$ & $\mathbf{4 3 . 7 \%}$ \\
\hline
\end{tabular}

Conforme podemos observar na tabela 3, percebemos que os candidatos encontram mais dificuldades em conceitos envolvendo a $3^{\mathrm{a}}$ Lei de Newton do que no tópico sobre processos de eletrização. Aproximadamente 63\% dos candidatos não conseguiram identificar as forças eletrostáticas que atuam no pente e no papel como um par açãoreação, soma dos percentuais das alternativas C e D. Enquanto somente perto de 25\% dos candidatos tiveram dificuldades em relação a eletrização, alternativas B e C.

Ao se observar a atratividade dos grupos socioeconômicos verificamos que a atratividade da alternativa correta (a A) aumenta de acordo com os grupos socioeconômicos enquanto que as atratividades das alternativas $\mathbf{C}$ - com as duas afirmativas erradas - e D - a mais sinalizada - decrescem.

Essa questão parece indicar uma característica comum freqüentemente observada nos estudantes: ver o ensino em fragmentos e ter dificuldades em associar conhecimentos abordados em tópicos distintos.

A última questão que iremos apresentar é de 2005 (Quadro 6) e aborda o conteúdo de circuitos elétricos de uma forma bem contextualizada. É apresentado um circuito de uma cozinha e solicita-se que os candidatos sinalizem a alteração nas correntes quando um dos aparelhos, que não estava em funcionamento, é ligado [ALVES et al., 2005].

Notamos, na Tabela 4, que a atratividade das alternativas em que as duas correntes são alteradas (a A) e a que nenhuma corrente é alterada (a $\mathbf{C}$ ) decrescem quando se vai para grupos socioeconômicos mais privilegiados. Esse fato nos leva a crer que os candidatos dos grupos menos privilegiados têm grande dificuldade com uma análise 


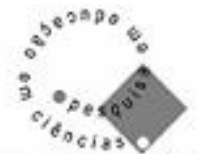 \\ ensa10}

Vol. 10 no. 1 jun. 2008

qualitativa de circuitos elétricos. É importante destacar que a alternativa $\mathbf{A}$ foi a de maior atratividade em quase todos os grupos.

Quadro 6 - Questão 14 do vestibular de 2005 que teve índice de discriminação de 0,37.

O circuito da rede elétrica de uma cozinha está representado, esquematicamente, nesta figura:

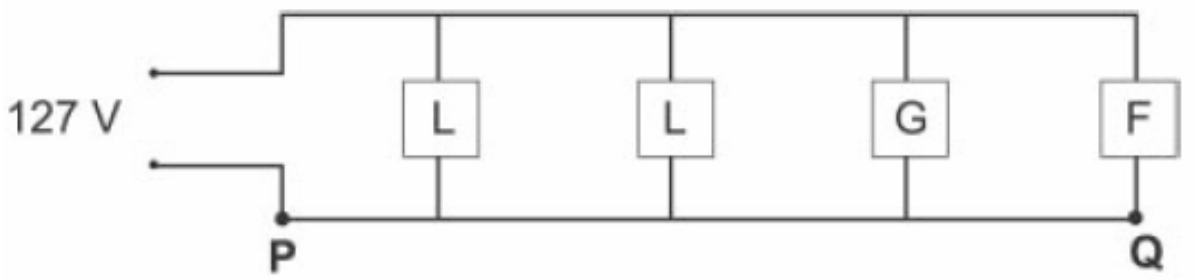

Nessa cozinha há duas lâmpadas $\mathbf{L}$, uma geladeira $\mathbf{G}$ e um forno elétrico $\mathbf{F}$. Considere que a diferença de potencial na rede elétrica é constante.

Inicialmente, apenas as lâmpadas e o forno estão em funcionamento. Nessa situação, as correntes elétricas nos pontos $\mathbf{P}$ e $\mathbf{Q}$, indicados na figura, são respectivamente, $\mathbf{i}_{\mathrm{P}}$ e $\mathbf{i}_{\mathrm{Q}}$.

Em um certo instante a geladeira entra em funcionamento.

Considerando-se essa nova situação, é CORRETO afirmar que:

A) $\mathbf{i}_{\mathrm{P}}$ e $\mathbf{i}_{\mathrm{Q}}$ se alteram.

B) apenas $\mathbf{i}_{\mathrm{P}}$ se altera.

C) $\mathbf{i}_{\mathrm{P}}$ e $\mathbf{i}_{Q}$ não se alteram.

D) apenas $\mathbf{i}_{Q}$ se altera.

Tabela 4: Atratividade das alternativas da questão 14/2005, de acordo com o grupo socioeconômico.

\begin{tabular}{||c|c|c|c|c|c|c|c|c|}
\hline \multirow{2}{*}{ Geral } & \multicolumn{3}{|c|}{ Escolas } & \multicolumn{4}{c|}{ Escolaridade Pais } \\
\cline { 2 - 9 } & Pública & Particular & Federal & Fundamental & Médio & Superior 1 & Superior 2 \\
\hline A & $\mathbf{3 0 . 1 \%}$ & $\underline{\mathbf{3 8 . 1 \%}}$ & $\underline{\mathbf{2 9 . 5 \%}}$ & $24.6 \%$ & $\underline{\mathbf{3 8 . 8 \%}}$ & $\underline{\mathbf{3 3 . 1} \%}$ & $\underline{\mathbf{3 0 . 2 \%}}$ & $27.5 \%$ \\
\hline B & $21.4 \%$ & $18.2 \%$ & $24.0 \%$ & $\underline{\mathbf{3 2 . 9 \%}}$ & $18.4 \%$ & $20.9 \%$ & $23.3 \%$ & $27.5 \%$ \\
\hline C & $20.4 \%$ & $22.5 \%$ & $18.5 \%$ & $14.8 \%$ & $22.4 \%$ & $20.8 \%$ & $18.9 \%$ & $16.6 \%$ \\
\hline D & $24.3 \%$ & $21.0 \%$ & $27.9 \%$ & $27.5 \%$ & $20.2 \%$ & $25.1 \%$ & $27.4 \%$ & $\underline{\mathbf{2 8 . 4 \%}}$ \\
\hline \hline
\end{tabular}

Por outro lado, a atratividade das alternativas $\mathbf{B}$ e $\mathbf{D}$ cresce com a escolaridade dos pais. O fato dos estudantes optarem por essas alternativas parece indicar que eles conseguem fazer uma melhor análise desse tipo de circuito. A alternativa $\mathbf{D}$ - embora 


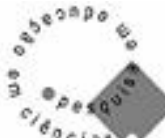 \\ ensa10}

Vol. 10 no. 1 jun. 2008

esteja errada - pode ser relacionada com o análogo hidrodinâmico, ou seja, considera uma fonte de corrente constante ao invés de uma fonte de tensão constante.

Chama a atenção o fato do grupo de estudantes de escolas federais ser o único que teve a maior atratividade na alternativa correta. Como já dissemos anteriormente, a maior parte desses estudantes realizou curso técnico na área de ciências exatas e, assim, tem maior contato com esse conteúdo.

\section{Conclusões e Perspectivas}

Neste trabalho introduzimos uma forma de análise para classificar os estudantes que se candidataram aos processos seletivos em uma escala crescente de domínio dos conhecimentos. É importante salientar que essa análise só tem valor devido ao grande número de estudantes - mais de 60 mil - que fizeram parte das amostragens o que permitiu que em cada grupo socioeconômico ainda houvesse um grande número de representantes.

Notamos que, se a classificação é feita através do tipo de escola freqüentada pelo candidato, nós conseguimos separar somente em dois grupos distintos - o de públicas estaduais/municipais com menor desempenho do que o de particulares ou públicas federais. No entanto, se o agrupamento é realizado usando a formação escolar dos pais dos candidatos, conseguimos uma clara separação em quatro grupos em que o desempenho aumenta de acordo com a escolaridade dos pais.

A forma de análise que introduzimos foi utilizado, de uma forma bem breve, em quatro situações:

- a identificação das forças que atuam em um corpo em movimento na qual os grupos menos favorecidos apresentam maior percentual de atração por concepções espontâneas errôneas e maior dificuldade em retirar informações do enunciado;

- em um problema de transformações termodinâmicas em que os grupos mais favorecidos tendem a apresentar mais domínio dos dois conceitos envolvidos - o de pressão e o de conservação de energia; 


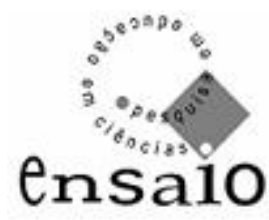

Vol. 10 no. 1 jun. 2008

- em uma situação envolvendo dois tópicos em física, um sobre eletrização e outro sobre $3^{\text {a }}$ Lei de Newton, foi possível perceber as dificuldades dos estudantes em identificar o par de forças ação e reação. Quase todos os grupos socioeconômicos tiveram maior atratividade na opção em que a afirmativa sobre essas forças não está correta.

- por último em um circuito elétrico residencial, os grupos socioeconômicos menos favorecidos apresentavam grande dificuldade de análise do problema e os mais favorecidos conseguiam uma maior elaboração, embora errônea (utilização do análogo hidrodinâmico).

Trabalhos mais detalhados sobre cada tópico tratado neste artigo estão sendo desenvolvidos. Nesses trabalhos, apresentamos várias questões de anos diferentes que abordam o mesmo conteúdo, às vezes de forma bem semelhante, e aplicamos a forma de análise que aqui introduzimos. Através do exame desses resultados, conseguimos levantar de forma mais clara as principais dificuldades que os estudantes têm no estudo desses tópicos.

\section{Referências}

ALVES, E.S.; et. al. - Física no vestibular: provas e comentários (Vestibular UFMG/2001); Belo Horizonte: Ed. UFMG; (2001)

ALVES, E.S.; et. al. - Física no vestibular: provas e comentários (Vestibular UFMG/2003); Belo Horizonte: Ed. UFMG; (2003)

ALVES, E.S.; et. al. - Física no vestibular: provas e comentários (Vestibular UFMG/2004); Belo Horizonte: Ed. UFMG; (2004)

ALVES, E.S.; et. al. - Física no vestibular: provas e comentários (Vestibular UFMG/2005); Belo Horizonte: Ed. UFMG; (2005)

HESTENES, D.; Wells, M.; Swackhamer, G. - Force Concept Inventory; Phys. Teach. 30: 141 (1992)

KALMAN, C. S.; ROHAR, S.; WELLS, M. - Enhancing conceptual change using argumentative essays. Am. J. Phys. 72 (5) (2004)

PACCA, J. L. A. . A Metodologia de Análise Nas Pesquisas Sobre Conceitos Alternativos. Revista de Ensino de Física, 1(1): 20-30 (1984) 


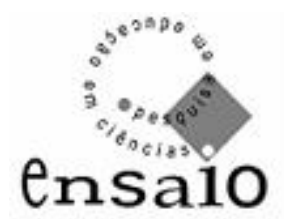

Vol. 10 no. 1 jun. 2008

PEDUZZI, L.O.Q.; MOREIRA, M.A.; ZYLBERSZTAJN, A. - As concepções espontâneas, a resolução de problemas e a história da ciência numa seqüência de conteúdos em mecânica: o referencial teórico e receptividade de estudantes universitários à abordagem histórica da relação força e movimento, Revista Brasileira Ensino Física, 14(4) 239-246 (1992)

SOUZA; E. V., MOREIRA J. G., Conceitos intuitivos: força no sentido do movimento em questões do vestibular da Universidade Federal de Minas Gerais, in Anais do IX Encontro de Pesquisa em Ensino de Física, Jabuticatubas, MG (2004)

VIENNOT L, European J Sci Ed (1) p. 205 (1979)

VILLANI, A. ; PACCA, J. L. A. ; HOSOUME, Y. . Concepção Espontânea Sobre Movimento. Revista de Ensino de Física, 7(1): 37-45 (1985).

ZYLBERSZTAJN, A. - Concepções Espontâneas em Física: Exemplos em Dinâmica e Implicações para o Ensino, Revista de Ensino de Física, 5(2): 3-16, (1983)

UFMG, Manual do Candidato do Concurso Vestibular (2005).

DATA DE RECEBIMENTO: 11/01/2007

DATA DE APROVAÇÃO: 23/08/2007

DATA DE VERSÃO FINAL: 21/09/2007 


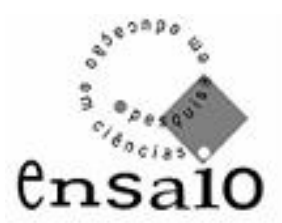

\section{Apêndice}

Vol. 10 no. 1 jun. 2008

A Tabela 5 apresenta dados dos vestibulares dos últimos anos: a linha hachurada apresenta, na $2^{\mathrm{a}}$ coluna, o total de candidatos e, nas outras colunas, os percentuais dentro de cada grupo socioeconômico; as linhas em branco mostram, na linha superior, as notas médias desses grupos no geral, ou seja, nas oito provas fechadas e, na linha inferior, a nota média na prova de Física.

Tabela 5: Número total de candidatos e distribuição pelos grupos socioeconômicos (linhas hachuradas) e notas média geral e na prova de Física para os anos de 200 a 2005.

\begin{tabular}{|c|c|c|c|c|c|c|c|c|}
\hline \multirow{2}{*}{} & & \multicolumn{3}{|c|}{ Escolas } & \multicolumn{4}{c|}{ Escolaridade Pais } \\
\cline { 2 - 9 } & & Pública & Particular & Federal & Fundamental & Médio & Superior 1 & Superior 2 \\
\hline 2000 & 71848 & $47.5 \%$ & $46.7 \%$ & $4.7 \%$ & $35.2 \%$ & $26.6 \%$ & $21.8 \%$ & $14.7 \%$ \\
\hline Geral & $48.2 \%$ & $42.8 \%$ & $53.3 \%$ & $55.5 \%$ & $40.0 \%$ & $48.0 \%$ & $52.0 \%$ & $57.8 \%$ \\
\hline Física & $40.3 \%$ & $34.7 \%$ & 46.05 & $49.8 \%$ & $34.1 \%$ & $40.5 \%$ & $45.0 \%$ & $50.3 \%$ \\
\hline 2001 & 72517 & $50.7 \%$ & $43.1 \%$ & $5.1 \%$ & $35.8 \%$ & $26.3 \%$ & $19.7 \%$ & $13.8 \%$ \\
\hline Geral & $45.0 \%$ & $41.0 \%$ & $50.5 \%$ & $52.3 \%$ & $39.1 \%$ & $44.7 \%$ & $49.5 \%$ & $54.7 \%$ \\
\hline Física & $36.1 \%$ & $32.6 \%$ & $41.2 \%$ & $44.5 \%$ & $30.6 \%$ & $35.5 \%$ & $40.4 \%$ & $45.7 \%$ \\
\hline 2002 & 73290 & $55.9 \%$ & $38.8 \%$ & $4.5 \%$ & $40.5 \%$ & $27.2 \%$ & $18.3 \%$ & $12.6 \%$ \\
\hline Geral & $47.2 \%$ & $41.3 \%$ & $55.3 \%$ & $58.3 \%$ & $39.9 \%$ & $47.5 \%$ & $54.1 \%$ & $60.7 \%$ \\
\hline Física & $39.8 \%$ & $33.8 \%$ & $47.8 \%$ & $53.5 \%$ & $32.5 \%$ & $39.9 \%$ & $46.7 \%$ & $53.7 \%$ \\
\hline 2003 & 72061 & $53.2 \%$ & $41.7 \%$ & $4.4 \%$ & $37.6 \%$ & $28.5 \%$ & $19.1 \%$ & $13.8 \%$ \\
\hline Geral & $48.7 \%$ & $42.9 \%$ & $55.7 \%$ & $53.1 \%$ & $42.0 \%$ & $48.8 \%$ & $54.4 \%$ & $59.9 \%$ \\
\hline Física & $44.8 \%$ & $37.6 \%$ & $52.9 \%$ & $59.9 \%$ & $36.7 \%$ & $44.7 \%$ & $51.8 \%$ & $57.8 \%$ \\
\hline 2004 & 65920 & $48.2 \%$ & $39.5 \%$ & $5.3 \%$ & $33.7 \%$ & $26.4 \%$ & $18.1 \%$ & $11.9 \%$ \\
\hline Geral & $47.2 \%$ & $41.9 \%$ & $53.0 \%$ & $52.4 \%$ & $41.7 \%$ & $46.7 \%$ & $51.9 \%$ & $57.4 \%$ \\
\hline Física & $33.5 \%$ & $28.7 \%$ & $38.5 \%$ & $40.5 \%$ & $28.4 \%$ & $32.9 \%$ & $37.7 \%$ & $43.5 \%$ \\
\hline 2005 & 66446 & $50.5 \%$ & $44.5 \%$ & $4.4 \%$ & $32.0 \%$ & $29.2 \%$ & $20.4 \%$ & $14.7 \%$ \\
\hline Geral & $47.5 \%$ & $41.1 \%$ & $53.7 \%$ & $57.8 \%$ & $40.5 \%$ & $47.0 \%$ & $52.4 \%$ & $57.9 \%$ \\
\hline Física & $40.1 \%$ & $34.7 \%$ & $45.3 \%$ & $52.0 \%$ & $34.0 \%$ & $40.1 \%$ & $44.4 \%$ & $49.0 \%$ \\
\hline
\end{tabular}

